\title{
LOS OTROS SIGNOS
}

\author{
CARLOS SÁEZ
}

Universidad de Alcalá

AMELIA GARCÍA MEDINA

Universidad de Alcalá ${ }^{2}$

\section{Resume}

Este artículo se centra en los signos o símbolos, presentes en los documentos y manuscritos medievales hispanos, cuya forma no deriva de la palabra subscripsi ni de las cruces. Habitualmente han sido tratados como meros elementos de validación de los diplomas. Pero estos elementos servían también de nexos de comunicación visual entre las clases altas capaces de producir escritos y los demás miembros de la sociedad medieval, en su mayoría analfabetos.

\section{Palabras Clave}

Cultura escrita, diplomática altomedieval, signos y símbolos.

\section{Abstract}

The aim of this article is to study the signs and symbols that appear in the hispanic medieval documents and manuscripts whose form does not derive from the word subscripsi or from the cross. These signs and symbols have usually been considered simply as mere elements to validate the charters. However, these elements were useful as a mean of visual communication between the high classes, able to generate charters, and the rest of medieval society, the majority illiterate.

\section{Key Words}

Written culture, Early Medieval diplomatics, Signs and symbols.

\footnotetext{
${ }^{1}$ Este trabajo se enmarca en el proyecto de investigación Usos, prácticas y modelos de conservación de lo escrito en la península ibérica entre los siglos XI a XVII, $\mathrm{n}^{\circ}$ de referencia BHA 2002-02541, financiado por el Ministerio de Ciencia y Tecnología, dirigido por Carlos Sáez (Universidad de Alcalá).

${ }^{2}$ Becaria FPU de la Universidad de Alcalá.
} 
$\mathrm{U}$ na de nuestras líneas de investigación se ha enfocado en los últimos tiempos hacia la interpretación de los signos diplomáticos de validación ${ }^{3}$. En varios lugares ha quedado demostrado que todos ellos encierran palabras en su trazado, en ocasiones sencillos pero en otras de gran complejidad ${ }^{4}$. La documentación diplomática hispana es muy rica en signos de validación, en especial entre los siglos VIII y XIII, aunque en los siguientes y hasta el XX todavía sea posible encontrar vestigios de los mismos en determinados documentos reales y notariales. Las dos formas más habituales que adoptan son la cruz ${ }^{5}$ la derivada de las tres eses de la palabra subscripsi $i^{6}$. Pero en esta ocasión vamos a hacer una primera tentativa de ordenación de los «otros signos», es decir, de aquellos que presentan formas externas diferentes, normalmente identificables con hechos $\mathrm{u}$ objetos de la vida cotidiana, o con costumbres escriturarias precisas.

Este tercer tipo de signos está formado por aquellos que se salen de la norma habitual y que requieren una explicación particular en cada caso. Su presencia en los documentos se explica porque los símbolos gráficos documentales suelen evolucionar y tienden a acercarse a arquetipos de fácil identificación: rectángulos, triángulos, pentágonos, cruces, estrellas, animales, figuras humanas, círculos, espirales $\mathrm{u}$ otros elementos que se manifiestan en los signos notariales de la Baja Edad Media en toda Europa. En Cataluña, por ejemplo, si los apellidos de los notarios correspondían a un objeto cuyo dibujo era factible, los notarios lo utilizaban en lugar del signo notarial habitual. Así, el notario apellidado «Pons» dibujaba un puente, «Serra» una sierra y «Esteller» una estrella ${ }^{7}$.

\footnotetext{
${ }^{3}$ Precursoras en este tema son las obras de Peter Rück, Die Urkunde als Kunstwerk, en Begegnung des Ostens und Westens um die Wende des ersten Jahrtausend, pp. 311-333, Köln 1991; (editor), Graphische Symbole in mittelalterlichen Urkunden, «Historische Hilfswissenschaften» 3, Marburg 1996; y, sobre los signos reales, Bildberichte vom König. Kanzlerzeichen, königliche Monogramme und das Signet der salischen Dynastie, Institut für Historische Hilfswissenschaften, Marburg an der Lahn, 1996 (elementa diplomatica 4).

${ }^{4}$ Carlos Sáez y Rogelio Pacheco Sampedro, Signos Diplomáticos y emblemática, Littera Scripta in homorem Prof. Lope Pascual Martínez, Universidad de Murcia 2002, vol. 2, pp. 963-982. Rogelio Pacheco Sampedro, El diploma del rey Silo. Datos de semiótica para un estudio diplomático, «Signo. Revista de Historia de la Cultura Escrita» 8 (2001) pp. 121-178.

${ }^{5}$ Rogelio Pacheco Sampedro y Carlos Sáez, Origen y evolución de la cruz como símbolo cristiano, Actas del II Congreso Internacional de Historia de la Vera Cruz, Caravaca de la Cruz (Murcia) 2001.

${ }^{6}$ Concepción Mendo Carmona, La suscripción altomedieval, «Signo. Revista de Historia de la Cultura Escrita» 4 (1997) pp. 9-20.

${ }^{7}$ Josep Trenchs Odena, reseña de la obra Signos notariales, Junta de Decanos de los Colegios Notariales de España, Centenario de la Ley del Notariado, Barcelona 1961, publicada en «Anuario de Estudios Medievales» 8 (1972-1973) pp. 703-704.
} 
Estos signos especiales comienzan a ser frecuentes en el noroeste peninsular, zona de nuestro interés, en la segunda mitad del siglo XI, es decir, cuando se inicia la decadencia del sistema semiótico de los reinos asturleonés y castellanoleonés. Sin embargo, es constatable que a lo largo del siglo $\mathrm{X}$ ya van apareciendo algunos ejemplos. Abordamos ya el estudio de estos signos, que hemos dividido en varios apartados $^{8}$.

\section{SIGNOS ANTROPOMÓRFICOS}

\subsection{Manos}

En las suscripciones abundan los ejemplos en los que se representan manos y brazos completos desde fines del siglo X hasta el XIII ${ }^{9}$. El signo consiste en el dibujo de la mano acompañando a la suscripción del escriba y tiene en nuestra opinión varias funciones. En primer lugar, hacer visible y recordar la conexión entre el texto y sus autores, cuya presencia evoca. Tal función es desempeñada tanto cuando aparece como signo del escriba (evocando el trazado material de la escritura), como cuando se presenta como signo del otorgante. $Y$ en segundo lugar, en este último caso parece evocar la imposición de la mano del otorgante sobre el documento entregado al destinatario. Mediante esta ceremonia el otorgante jura el contenido del documento ratificando su contenido jurídico. Es frecuente encontrar estos signos en documentación gallega, aunque también se hallan en los restantes reinos norteños y en la Corona de Aragón. Es especialmente significativa su presencia en documentos del monasterio gallego de Caaveiro (Figura $1^{10}$ ).

Asimismo, tanto en León y Galicia como en Portugal aparecen brazos completos, en ocasiones sosteniendo algún objeto. Un notario gallego del siglo XIII presenta un brazo y una mano que en su palma parece tener un objeto alargado (Figura 2). Entre los obispos hallamos una mano sostiene un báculo o bastón, en señal de dominio (Figura 3). También encontramos un notario leonés que con dos dedos sostiene una flor con intención que no podemos interpretar (Figura 4).

\footnotetext{
${ }^{8}$ Como hemos indicado, ésta es una primera tentativa de organizar estos signos que seguramente exigirá modificaciones en futuras investigaciones.

${ }^{9}$ Sobre este motivo puede verse el trabajo de Rogelio Pacheco Sampedro, El signum manuum en el cartulario del monasterio de San Juan de Caaveiro (s. IX-XIII), «Signo. Revista de Historia de la Cultura Escrita» 4 (1997) pp. 27-37.

${ }^{10} \mathrm{El}$ signo representa una mano sobre un libro, seguramente la Biblia, en actitud de juramento.
} 
Por último, aparecen manos muy ocasionalmente en signos derivados de la abreviatura de la palabra subscripsi, en el lugar en que suelen situarse la espiral y los bucles que en otros trabajos hemos interpretado como equivalentes a confirmans manu. En las Figuras 5 y 6 puede comprobarse que efectivamente los bucles situados sobre la abreviatura de confirmans derivan de una estilización de la mano.

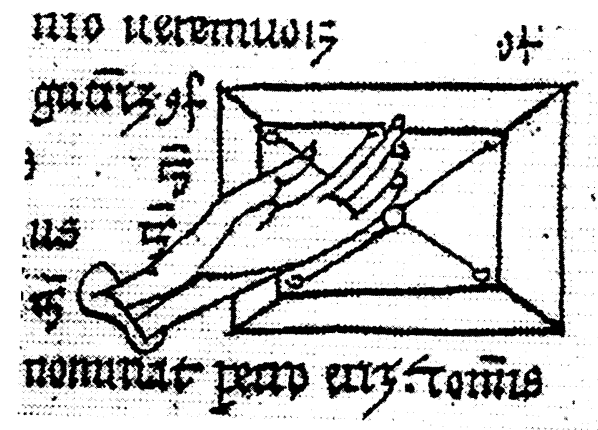

Figura 1.- Mano de Caaveiro.

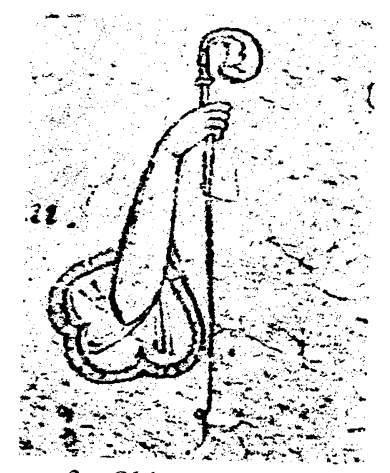

Figura 3.- Obispo Diego de León.

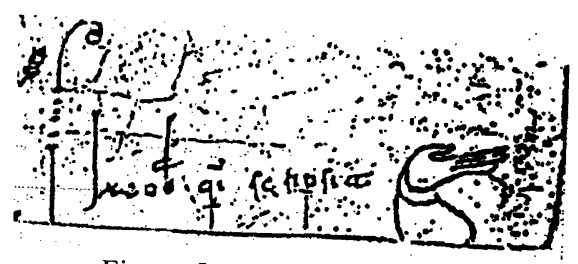

Figura 5.- Mano en subscripsi.

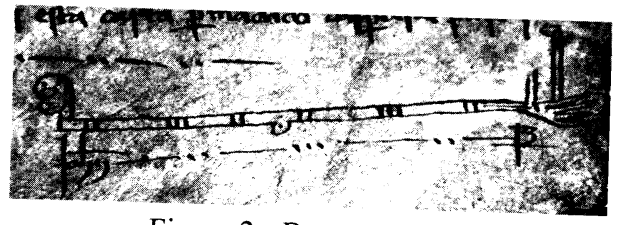

Figura 2.- Brazo y mano.

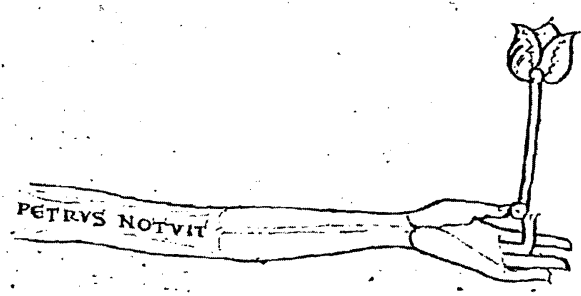

Figura 4.- Pedro, notario leonés.

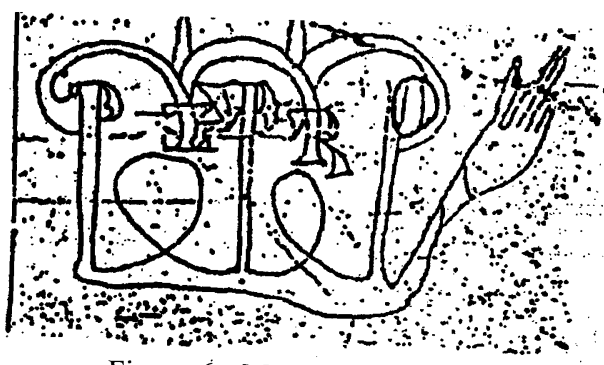

Figura 6.- Mano en subscripsi. 


\subsection{Cabezas}

En otros casos encontramos ejemplos en los que también se evoca la persona del otorgante mediante un «retrato» más o menos convencional de éste o si acaso del copista del diploma. La presencia de estas imágenes se explica tanto por la necesidad de recordar a la persona del otorgante como por la ausencia de originalidad de los documentos que incluyen este recurso gráfico. Se trataría, por tanto, de un medio de intensificar o reforzar la conexión entre autor y documento en una época que desconoce medios públicos de certificar la veracidad de copias y traslados ${ }^{11}$. Estos retratos pueden hallarse tanto en documentos asturianos $\mathrm{y}$ leoneses como navarro-aragoneses (Figuras 7 y 8). Los documentos en los que aparecen son en ocasiones refacciones. Por ello la presencia de este motivo sin duda obedece a que la no originalidad de los documentos se vea paliada y su validez reforzada por la evocación visual de su otorgante. Pero otras veces, como en el caso del asturiano Pelayo, los documentos son originales (Figura $9^{12}$ ).

Algunos obispos de León emplean un signo mixto en el que figuran su cabeza con mitra representando la imagen del suscribiente, y sus manos extendidas, posiblemente en señal de juramento (Figuras 10 y 11).

Los signos antropomorfos de cuerpo completo son muy raros y sólo hemos encontrado un caso (Figura 12) en el que el copista aparece tumbado sujetando entre sus manos lo que parece un pergamino con la leyenda de su suscripción.

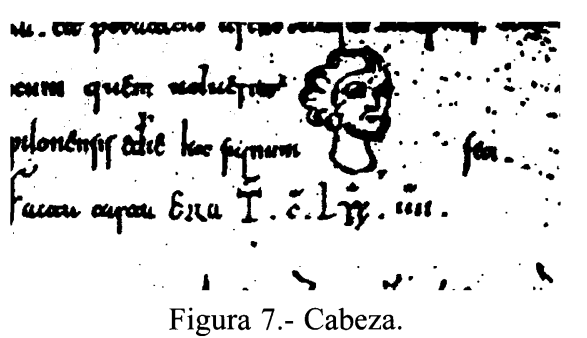

Figura 7.- Cabeza.

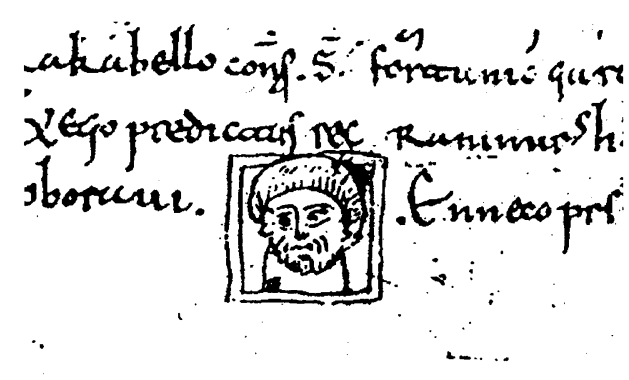

Figura 8.- Cabeza.

\footnotetext{
${ }^{11}$ Luis Casado Otaola, Per visibilia ad invisibilia: Representaciones figurativas en documentos altomedievales como símbolos de validación y autoría, «Signo. Revista de Historia de la Cultura Escrita» 4 (1997) pp. 39-56.

${ }^{12}$ En la suscripción se lee: Pelagius kanonicus ovetensis notuit.
} 


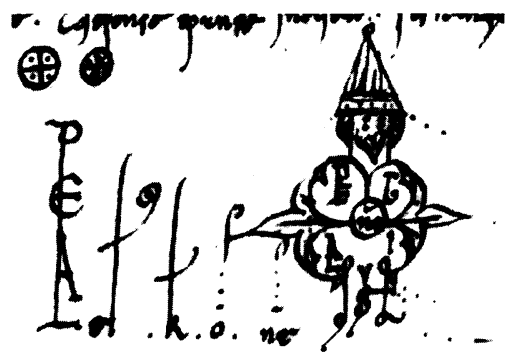

Figura 9.- Pelayo, canónigo de Oviedo.

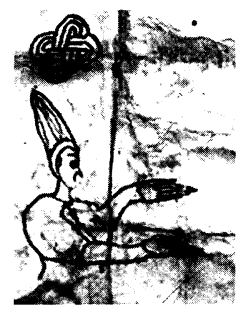

Figura 10.- Obispo de León con mitra.

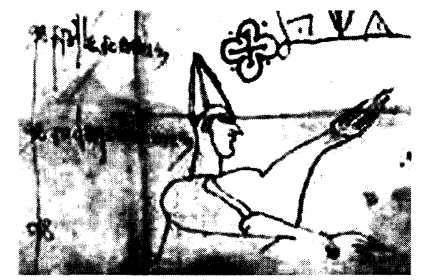

Figura 11.- Obispo de León con mitra.

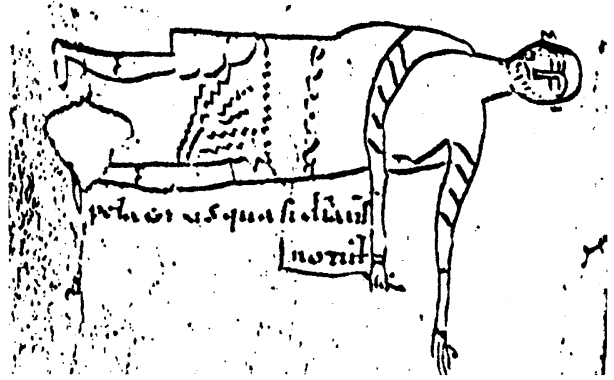

Figura 12.- Pelayo, copista tumbado.

\section{ANIMALES}

Son raras las representaciones de signos con formas animales. Sólo hemos hallado unos pocos. Uno de ellos es el signo de los condes de Cabrera, catalanes de origen afincados en Zamora, que representa una cabra alusiva a su apellido (Figura 13). Un perro aparece en dos ocasiones, como emblema de un notario portugués y de otro gallego, este algo tardío, de finales del siglo XIII (Figuras 14 y 15). Además hemos constatado que en Cataluña algunos notarios utilizan aves, probablemente halcones, como signos. Aparte quedan los característicos leones de las ruedas reales castellano leonesas, de las que nos hemos ocupado en otras ocasiones ${ }^{13}$.

\footnotetext{
${ }^{13}$ Carlos Sáez, Documentos para ver, documentos para leer, «Anuario de Estudios Medievales» 29 (1999) pp. 899-915.
} 


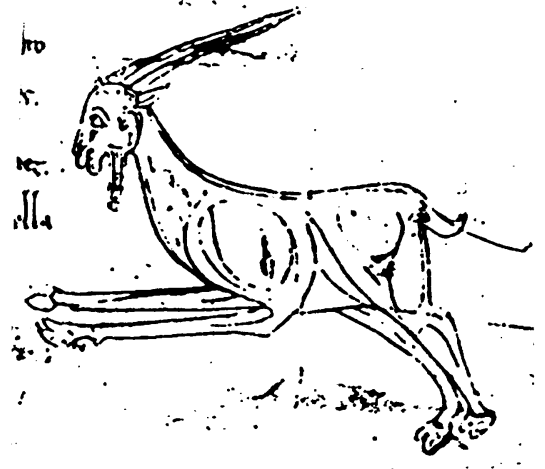

Figura 13.- Cabra, condes de Cabrera.

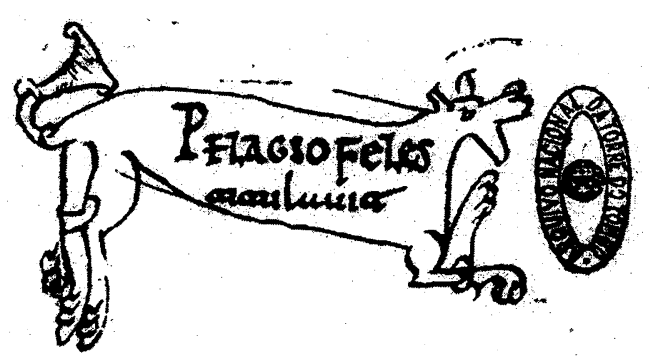

Figura 14.- Perro, notario portugués.

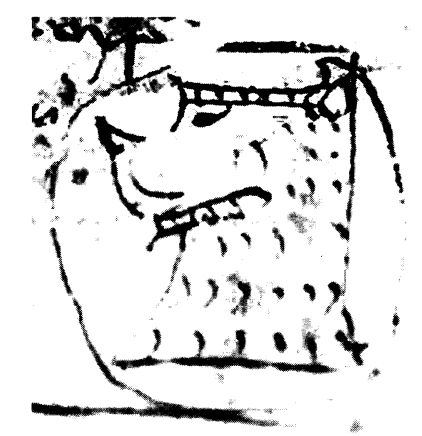

Figura 15.- Perro, notario gallego.

\section{EDIFICIOS}

Muy rara vez hemos hallado algún signo en forma de edificio, normalmente un castillo, motivo que aparece en varias ocasiones (Figura 16). Es posible que representen algún edificio del lugar de residencia del notario.

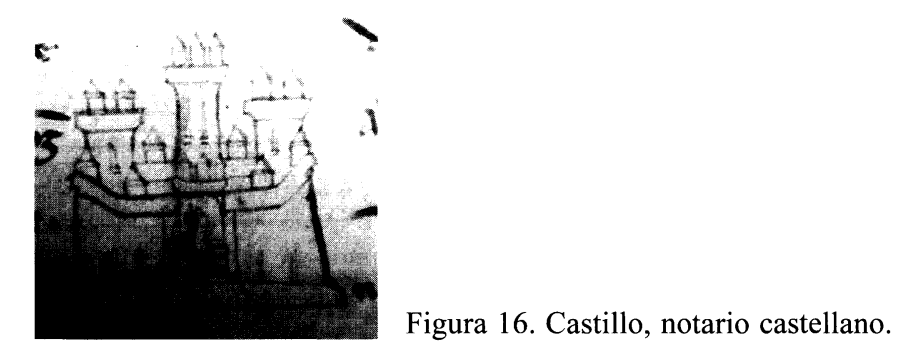

Cuadernos de Estudios Gallegos, Tomo LI, Fascículo 117, Santiago 2004 . (Págs. 207 - 218) 


\section{ESTRELLAS}

En los documentos aparecen estrellas de cuatro, cinco y seis puntas. Es posible que sean elementos de procedencia mozárabe ya que se encuentran con frecuencia en los documentos del monasterio leonés de Abeliar, que contaba con una importante comunidad mozárabe, y era empleado normalmente por suscriptores de tal origen. Refuerza esta idea el hecho de que el mismo signo se documente en una huesa, homóplato bovino usado para escribir, que contiene un alfabeto árabe. Pero el signo tiene una tradición más amplia pues perdura durante la baja Edad Media (Figuras 17 y 18). Asimismo, la estrella de cinco puntas o pentalfa parece que tuvo un valor mágico, como demuestra la pizarra de Carrio (siglo X, Asturias), que contiene un conjuro contra el granizo que va acompañado por varios de estos signos.

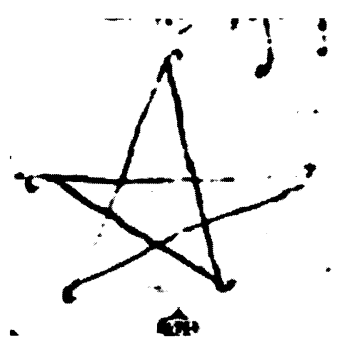

Figura 17.- Elías deán de Santiago.

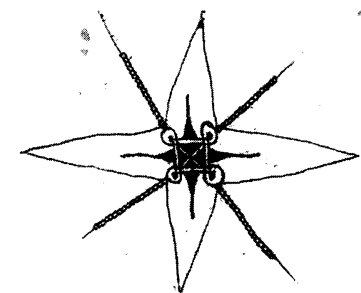

Figura 18.- Notario de Alcalá de Henares, siglo XV.

\section{SIGNOS RODADOS}

Con independencia de los signos reales, que han sido objeto de estudios varios ${ }^{14}$, también en documentos eclesiásticos y privados aparecen signos redondos, en especial en tierras gallegas. El obispo de Santiago de Compostela Diego Gelmírez, luego arzobispo, fue el primero que adopta la rota papal como signo de validación. En la Figura $19^{15}$ podemos ver la primera rueda hispana conocida. De su cancillería

${ }^{14}$ Martín Fuertes, José Antonio, El signum regis en el reino de León (1157-1230). Notas sobre su simbolismo, en Graphische Symbole in mittelalterlichen Urkunden, «Historische Hilfswissenschaften» 3, Marburg 1996. ..., pp. 463-478. Faustino Menéndez Pidal de Navascués, Heráldica medieval española, I. La casa real de León y Castilla, Hidalguía, Instituto Salazar y Castro (CSIC) Madrid 1982 y Leones y castillos. Emblemas heráldicos en España, Real Academia de la Historia, Madrid 1999.

${ }^{15}$ Signo rodado de Gelmírez, todavía obispo, copiado de una rota papal. Las leyendas dicen: (Dentro de la rueda) Uerbo Domini celi firmati sunt. (En la rueda, en el centro) D[idacus] (en los cuatro brazos) piscopus II. 
pasará a la real leonesa y de ahí a la castellana. Pero también otros prelados gallegos y algunos notarios adoptaron signos redondos, probablemente por el prestigio y la imagen de probada autoridad que tenía este signo. Entre los notarios elegimos un documento procedente del monasterio gallego de Carboeiro, con forma redonda pero con características peculiares (Figura 20).

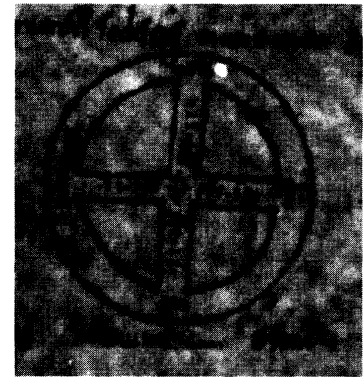

Figura 19.- Obispo Gelmírez.

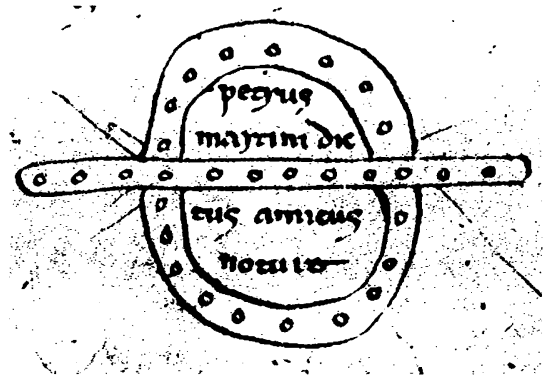

Figura 20.- Notario de Carboeiro.

\section{SIGNOS MONOGRAMÁTICOS}

A pesar de que las posibilidades gráficas a la hora de ejecutar los signos de suscripción eran variadas, los símbolos resultantes eran en general bastante parecidos entre sí, por lo que podía existir una posibilidad de confusión entre ellos. Por esta razón, para aumentar la distinción entre ellos, se fueron añadiendo al signo las letras del nombre del suscriptor sobre la base de los signos derivados de la palabra subscripsi. En el siglo $\mathrm{X}$ registran aun pocos monogramas, que corresponden tanto a suscripciones de testigos como de escribas y notarios. La mayoría son imperfectos, es decir sólo aparece en ellos una parte de las letras del nombre, aunque también hay algún caso de monograma completo. Durante el siglo XI el empleo de monogramas es mucho más frecuente. Suelen incluir el nombre completo del suscriptor y parecen predominar en la suscripción notarial, mientras que su uso desaparece poco a poco en las suscripciones de testigos.

Usaron signos monogramáticos personajes de relevancia, como los reyes de nombre Vermudo y Sancho o el notario Sampiro. Pero aquí pondremos otros ejemplos de personas menos conocidas, los signos de Albito, Donnigo y Fromarico, este último a la vez monogramático y criptográfico (Figuras $21-23^{16}$ ).

\footnotetext{
${ }^{16}$ En los signos se lee: Albito. Donnigus. Fromar-icus, estas últimas letras criptográficas.
} 
Hay otros signos más simples, que se contentan con reproducir el nombre completo del suscriptor, normalmente el scriptor, rodeado por trazos y adornos varios (Figura 24).

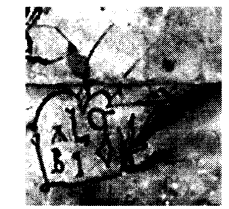

Figura 21.- Albito.

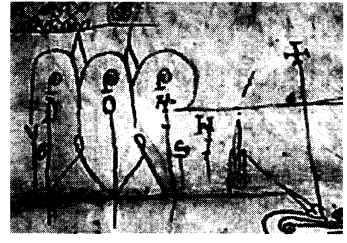

Figura 22.- Donnigo.

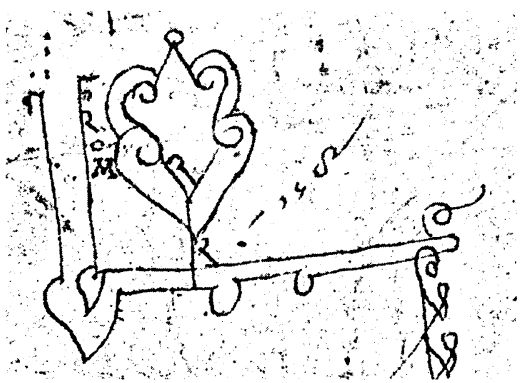

Figura 23.- Fromarico.

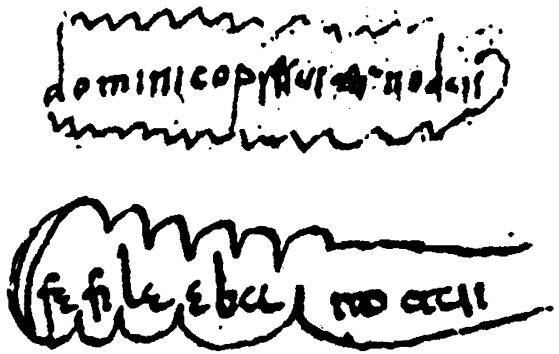

Figura 24.- Dominico y Fafila.

\section{OTROS SIGNOS}

Además de los símbolos descritos, la documentación presenta otros que por diversas causas por el momento no podemos reunir para formar grupos. Algunos aparecen de forma muy exigua y otros son muy tardíos y más propios de la Baja Edad Media, período que se sale de nuestros intereses en este momento. Pero a modo e ejemplos mencionaremos algunos de ellos.

Es posible que los signos que portan escritura criptográfica puedan llegar a formar grupo. Ya antes se ha citado algún caso y añadimos aquí el del copista gallego Cresconio, que a un signo de difícil interpretación añade su nombre -Cresconius - en esta escritura (Figura 25). Normalmente estos signos reproducen la palabra mutans o el nombre del copista en cifra. Pero además hemos hallado otros motivos en la documentación, como los emblemas heráldicos de algunos notarios nobiliarios, espadas en el cartulario de Celanova, signos mixtos, como una estrella unida a lo que parece una lanza (Figura 26), o figuras geométricas y artísticas que darán origen a signos bajomedievales (Figura 27), entre otros motivos que podríamos mencionar. 
Caso especial son las señales tardías de los notarios eclesiásticos que suelen presentar una iconografía particular. En ellas vemos aparecer habitualmente un altar al que se accede por cuatro escalones, que algunos han interpretado como símbolo de los cuatro evangelios, las llaves de San Pedro y alguna cruz, junto a otros elementos semióticos comunes a otros signos (Figura 28). Es posible que el particular signo del infante Fernando, hijo de Alfonso VII, pertenezca a este grupo (Figura 29).

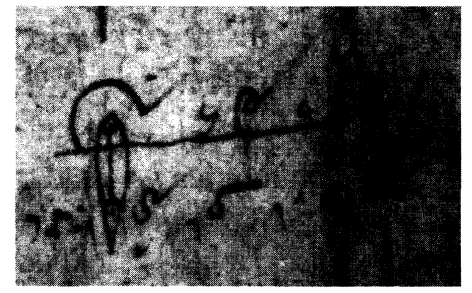

Figura 25.- Cresconius.

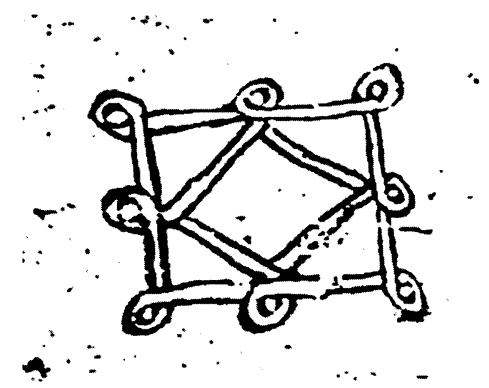

Figura 27.- Signo figurativo.

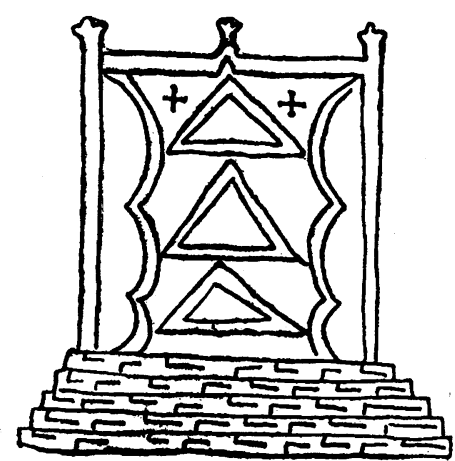

Figura 29.- Fernando, hijo de Alfonso VII.

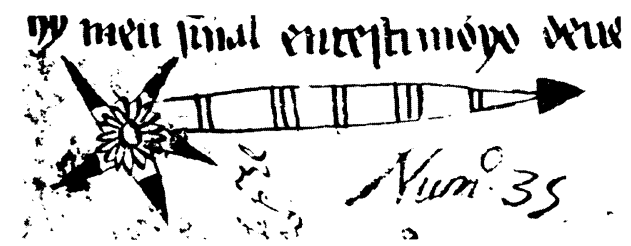

Figura 26.- Estrella-lanza.

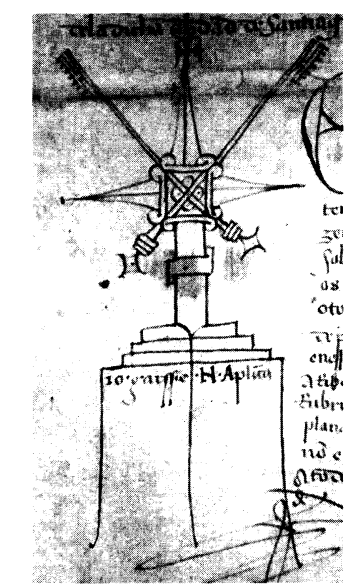

Figura 28.- Notario apostólico. 


\section{CONCLUSIÓN}

Sabemos que los signos de los que hemos escrito no fueron usados sólo como elementos diplomáticos. La propia documentación altomedieval suele dar información sobre su utilización en objetos varios como marca de propiedad. Por ejemplo, en el 914 el obispo Sisnando de Santiago pone su signo a una copa de plata de gran valor, y poco más tarde San Rosendo marca una aceña que se vendía con el suyo propio. La sociedad se basó con frecuencia en lo visual e icónico y el uso de signos fue más general de lo que parece. Por tanto, los símbolos escritos constituyen en la Edad Media una convención aceptada por todos como elemento conductor de la vida de la comunidad, incluidos sus miembros analfabetos, que ven y comprenden el valor de estos emblemas. Por ello el documento tiene una función icónica y visual que se desarrolla en determinadas ceremonias, como la lectura en público en voz alta ${ }^{17}$. Los los signos que hemos repasado en las páginas que preceden son prueba de ello. $\mathrm{Y}$, como otros muchos emblemas, constituyen una parcela de la historia de la humanidad cuyo estudio e interpretación merecen mayor interés del que hasta ahora se le ha dedicado.

\footnotetext{
${ }^{17}$ Sobre esta cuestión pueden verse varias de las obras de Roger Wright, y entre ellas La Traducción entre el Latín y el Romance en la Alta Edad Media, «Signo. Revista de Historia de la Cultura Escrita» 6 (1999) pp. 39-60.
}

Cuadernos de Estudios Gallegos, Tomo LI, Fascículo 117, Santiago 2004 . (Págs. 207 - 218) 